\title{
Enhanced Endocannabinoid Signaling Elevates Neuronal Excitability in Fragile X Syndrome
}

\author{
Longhua Zhang and Bradley E. Alger \\ Department of Physiology, Program in Neuroscience, University of Maryland School of Medicine, Baltimore, Maryland 21201
}

Fragile X syndrome (FXS) results from deficiency of fragile X mental retardation protein (FMRP). FXS is the most common heritable form of mental retardation, and is associated with the occurrence of seizures. Factors responsible for initiating FXS-related hyperexcitability are poorly understood. Many protein-synthesis-dependent functions of group I metabotropic glutamate receptors (Gp1 mGluRs) are exaggerated in FXS. Gp1 mGluR activation can mobilize endocannabinoids (eCBs) in the hippocampus and thereby increase excitability, but whether FMRP affects eCBs is unknown. We studied Fmr1 knock-out (KO) mice lacking FMRP to test the hypothesis that eCB function is altered in FXS. Whole-cell evoked IPSCs (eIPSCs) and field potentials were recorded in the CA1 region of acute hippocampal slices. Three eCB-mediated responses were examined: depolarization-induced suppression of inhibition (DSI), mGluR-initiated eCBdependent inhibitory short-term depression (eCB-iSTD), and eCB-dependent inhibitory long-term depression (eCB-iLTD). Low concentrations of a Gp1 mGluR agonist produced larger eCB-mediated responses in Fmr1 KO mice than in wild-type (WT) mice, without affecting DSI. Western blots revealed that levels of mGluR1, mGluR5, or cannabinoid receptor (CB1R) were unchanged in Fmr1 KO animals, suggesting that the coupling between mGluR activation and $\mathrm{CCB}$ mobilization was enhanced by FMRP deletion. The increased susceptibility of Fmr1 KO slices to eCB-iLTD was physiologically relevant, since long-term potentiation of EPSP-spike (E-S) coupling induced by the mGluR agonist was markedly larger in Fmr1 KO mice than in WT animals. Alterations in eCB signaling could contribute to the cognitive dysfunction associated with FXS.

\section{Introduction}

Fragile X syndrome (FXS) is often accompanied by neuropsychiatric problems such as hyperactivity, autism, attention disorders, and seizures (de Vries et al., 1998; Jin and Warren, 2000). FXS is typically caused by a trinucleotide repeat expansion on the $\mathrm{X}$ chromosome that causes epigenetic silencing of the Fmrl gene and prevents expression of the encoded protein, fragile X mental retardation protein (FMRP). Knock-out of the Fmrl gene in mice removes FMRP and mimics FXS in humans (O'Donnell and Warren, 2002).

FMRP associates with translating polyribosomes and a subset of brain mRNAs, and negatively regulates protein synthesis (Feng et al., 1997; Brown et al., 2001). Activation of group I metabotropic glutamate receptors ( $\mathrm{Gp} 1 \mathrm{mGluRs}$ ) leads to protein-synthesisdependent synaptic plasticity, where local synaptic control of protein synthesis is required for stable expression of long-term depression (LTD) (Weiler and Greenough, 1993; Merlin et al., 1998; Huber et al., 2000; Bear et al., 2004). FMRP is synthesized in response to mGluR activation (Weiler and Greenough, 1999). In Fmr1 knockout (KO) mice, Gp1 mGluR-dependent hippocampal LTD is en-

Received Feb. 12, 2010; revised; accepted March 19, 2010.

This work was supported by National Institutes of Health Grants R01 DA014625 and R01 MH077277 (B.E.A.). We thank M. Karson, J. Kim, D. Nagode, A. Tang, and M. Wang for their comments on a draft of this manuscript. We are indebted to Dr. Mary McKenna for her generosity in providing the Fmr1 knock-out and wild-type $57 \mathrm{BL} / 6 \mathrm{~J}$ mice.

Correspondence should be addressed to Dr. Bradley E. Alger, Department of Physiology, University of Maryland School of Medicine, Bressler Research Building, Room 5-025, 655 West Baltimore Street, Baltimore, MD 21201. E-mail: balgerlab@gmail.com.

DOI:10.1523/JNEUROSCI.0795-10.2010

Copyright $\odot 2010$ the authors $\quad 0270-6474 / 10 / 305724-06 \$ 15.00 / 0$ hanced (Huber et al., 2002), probably because of alterations in local protein synthesis (Bear et al., 2004; Pfeiffer and Huber, 2006; Dölen et al., 2007). Consistent with the "mGluR theory of fragile X" (Bear et al., 2004), increased protein synthesis occurs with mGluR stimulation in the absence of FMRP (Chuang et al., 2005; Koekkoek et al., 2005; Hou et al., 2006). As a consequence, a persistent, voltage-gated cation current becomes activated by Gp1 mGluRs, and accounts for prolonged epileptiform discharges in Fmr1 KO mice (Chuang et al., 2005; Bianchi et al., 2009). Whether the initial tendency to hyperexcitability in FXS can be fully explained by this mechanism is unclear.

Activation of Gp1 mGluRs also mobilizes endocannabinoids (eCBs) (Maejima et al., 2001; Varma et al., 2001), which activate CB1Rs on presynaptic cholecystokinin (CCK) interneuron terminals in hippocampus and suppress GABA release (Katona et al., 1999; Wilson et al., 2001). ("Mobilization" refers to eCB synthesis and release, which cannot be distinguished in electrophysiological experiments.) In CA1, activation of Gp1 mGluRs induces both eCB-dependent inhibitory short-term depression (eCB-iSTD) and eCB-dependent inhibitory long-term depression (eCB-iLTD) at CCK cell synapses. $\mathrm{Ca}^{2+}$-dependent eCB mobilization [depolarization-induced suppression of inhibition (DSI)] (review by Alger, 2002) facilitates LTP induction at glutamatergic synapses (Carlson et al., 2002), and eCB-iLTD underlies long-term changes of pyramidal cell excitability by increasing EPSPspike (E-S) coupling potentiation (Chevaleyre and Castillo, 2003).

Despite intense study of the eCB system (Piomelli, 2003), it is not known whether proteins downstream of mGluRs can influence eCB mobilization. The important role of mGluRs in both $\mathrm{eCB}$ and protein synthesis, together with evidence that certain 
cognitive deficits may result from disordered CB1-mediated signaling, suggests that FMRP deficiency could alter Gp1 mGluRdependent eCB mobilization. We have tested this hypothesis in mouse hippocampal slices and find that FMRP deficiency does not affect $\mathrm{Ca}^{2+}$-dependent release of eCB, or CB1Rs, but enhances the coupling between $\mathrm{Gp} 1 \mathrm{mGluRs}$ and $\mathrm{eCB}$ mobilization. The results may have significant implications for understanding both FXS and eCB signaling.

\section{Materials and Methods}

Animals. We used tissue from 2- to 4-month-old male Fmr1 KO and age-matched wild-type (WT) mice on the identical background strain, C57BL/6J (kindly provided by M. McKenna, University of Maryland, Baltimore, MD), and mGluR1 ${ }^{-1-}$ (from F. Conquet, University of Lausanne, Lausanne, Switzerland) and mGluR5 ${ }^{-1-}$ (from Jackson Laboratory) mice. To test the generality of the (S)-3,5-dihydroxyphenylglycine (DHPG) sensitivity, in a number of experiments we also used 2- to 4-month-old mice (from Charles River) of the C57BL/6N (males), 129Sv (female), and CD1 (female) strains. Unless otherwise noted in the text, "WT" refers to C57BL/6J WT mice. All experimental protocols were reviewed and approved by the University of Maryland School of Medicine Institutional Animal Care and Use Committee, and all animal handling was conducted in accordance with national and international guidelines. The number of animals used was minimized, and all necessary precautions were taken to mitigate pain or suffering.

Preparation of slices. Mice were deeply sedated with isoflurane and decapitated. Slices, $400 \mu \mathrm{m}$ thick, were cut on a Vibratome (model VT1200s, Leica Microsystems) in an ice-cold extracellular recording solution. Slices were stored in a holding chamber on filter paper at the interface of this solution and a moist, oxygenated atmosphere at room temperature for $\geq 1 \mathrm{~h}$ before transfer to the recording chamber (RC-27L, Warner Instruments) and warmed to $30^{\circ} \mathrm{C}$. The extracellular solution contained the following (in mM): $120 \mathrm{NaCl}, 3 \mathrm{KCl}, 2.5 \mathrm{CaCl}_{2}, 2 \mathrm{MgSO}_{4}, 1$ $\mathrm{NaH}_{2} \mathrm{PO}_{4}, 25 \mathrm{NaHCO}_{3}$, and 20 glucose, and was bubbled with $95 \% \mathrm{O}_{2}$, $5 \% \mathrm{CO}_{2}$, pH 7.4.

Electrophysiology. Whole-cell pipettes were pulled from thin wall glass capillaries (1.5 O.D., World Precision Instruments). Electrode resistances in the bath were 3-6 M $\Omega$ with internal solution containing the following (in mM): $90 \mathrm{CsCH}_{3} \mathrm{SO}_{4}, 1 \mathrm{MgCl}_{2}, 50 \mathrm{CsCl}, 2 \mathrm{MgATP}, 0.2$ $\mathrm{Cs}_{4}$-BAPTA, 10 HEPES, 0.3 Tris GTP, and 5 QX314. If the series resistances changed by $>20 \%$, the data were discarded. Data were collected with an Axopatch 1C amplifier (Molecular Devices), filtered at $1 \mathrm{kHz}$, and digitized at $5 \mathrm{kHz}$ using a Digidata 1200 (Molecular Devices) and Clampex 8 software (Molecular Devices). 2,3-Dihydroxy-6-nitro-7sulfamoyl-benzo[f]quinoxaline-2,3-dione (NBQX) $(10 \mu \mathrm{M})$ and D-AP5 $(20 \mu \mathrm{M})$ were present in all whole-cell experiments to block glutamatergic EPSCs. Monosynaptic evoked IPSCs (eIPSCs) were elicited by 100$\mu$ s-long extracellular stimuli delivered at $0.25 \mathrm{~Hz}$ with concentric bipolar stimulating electrodes placed in stratum radiatum (s. radiatum).

Slices were pretreated with $\omega$-agatoxin GVIA (agatoxin, $300 \mathrm{~nm}$ ) to reduce the contribution of eCB-insensitive eIPSCs (Lenz et al., 1998; Wilson et al., 2001). Stimulation in s. radiatum elicited eIPSCs every $4 \mathrm{~s}$, and at $90 \mathrm{~s}$ intervals, the pyramidal cell was depolarized to $0 \mathrm{mV}$ for $1 \mathrm{~s}$ to open voltage-gated calcium channels, increase $\left[\mathrm{Ca}^{2+}\right]_{\mathrm{i}}$, and induce DSI. The magnitude of DSI was calculated as follows: [( eIPSC $_{C}-$ eIPSC $\left._{T}\right) /$ eIPSC $\left._{C}\right] \times 100 \%$, where eIPSC $C_{C}$ is the mean amplitude of 8 eIPSCs before depolarization and eIPSC $_{\mathrm{T}}$ is the mean amplitude of 3 eIPSCs after depolarization. The "DSI integral" (e.g., Fig. 2D) was calculated as the percentage of eIPSC reduction (assumed constant during each $4 \mathrm{~s}$ time bin between stimuli) summed across all bins from time 0 (the end of the DSI step) until $90 \mathrm{~s}$ after the step.

For field potential recording, stimuli were delivered at $0.05 \mathrm{~Hz}$, and NBQX and D-AP5 were omitted. Field pipettes were filled with extracellular solution and placed in CA1 s. pyramidale to record both field EPSPs (fEPSPs) and population spikes (PSs). The stimulation strength was adjusted to produce PS amplitudes $30-40 \%$ of maximal. The E-S coupling magnitude was calculated as PS amplitude/fEPSP slope and expressed as percentage of the baseline value.
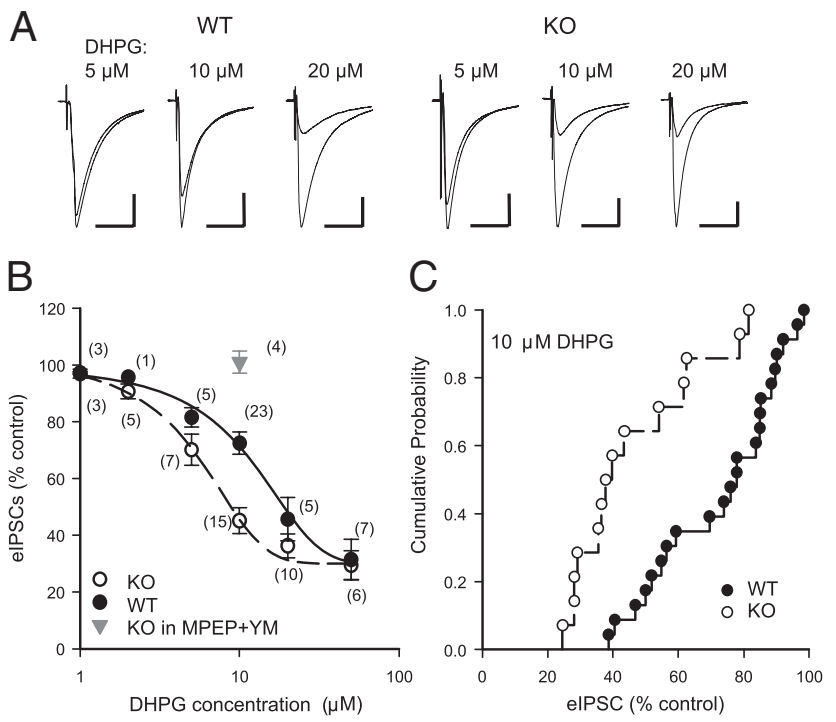

Figure 1. Fmr1 K0 neurons are more sensitive than (57BL/6J WT neurons to DHPG-induced eCB mobilization. $\boldsymbol{A}$, Representative traces showing elPSC suppression caused by DHPG in Fmr1 KO and WT mice. Calibration: 200 pA, 50 ms. B, Concentration-response curves of DHPGinduced elPSC suppression in Fmr $1 \mathrm{KO}$ and WT mice. At $10 \mu \mathrm{m}$ the differences were greatest (WT mice: $72.5 \pm 3.9 \%, n=23$; Fmr1 K0 mice: $45.2 \pm 4.6 \%, n=15, p<0.01)$. Pretreatment and bath application of the Gp1 mGluR antagonists MPEP (10 $\mu \mathrm{M})$ and YM298198 $(4 \mu \mathrm{M})$ blocked the suppressive effect of $10 \mu \mathrm{m}$ DHPG in Fmr1 K0 mice (gray triangle, $101.0 \pm 3.9 \%, n=4$ ). C, Cumulative probability plot of elPSC suppression induced by $10 \mu \mathrm{M}$ DHPG (difference between groups significant by $\mathrm{K}-\mathrm{S}$ test; $p<0.01)$.

Western blot. Hippocampi were quickly removed after decapitation and homogenized in RIPA buffer (Tris, $\mathrm{NaCl}, \mathrm{H}_{2} \mathrm{O}$, Igepal CA630, deoxycholic acid, EDTA, protease inhibitor, and phosphatase inhibitor). Homogenates were centrifuged at $9000 \times g$ for $30 \mathrm{~min}$ at $4^{\circ} \mathrm{C}$. Protein concentrations of supernatants were determined using the Bradford method with bovine serum albumin as standard. Samples $(10 \mu \mathrm{g} / \mu \mathrm{l})$ were denatured by heat, run on an SDS-PAGE gel (4-12\% Bis-Tris; Invitrogen), and transferred onto PVDF membranes (Invitrogen). Membranes were washed in T-TBS, blocked in $5 \%$ or $10 \%$ milk for $1 \mathrm{~h}$, and probed with a rabbit anti-CB1R (1:1000, Calbiochem, EMD4Biosciences), a rabbit anti-mGluR5 (1:5000, Millipore Biotechnology), or a rabbit anti-mGluR1 (1:1000, Millipore Biotechnology) polyclonal antibody overnight at $4^{\circ} \mathrm{C}$. They were then washed $3 \times$ in T-TBS, exposed to HRP-conjugated anti-rabbit IgG (1:3000) for $30 \mathrm{~min}$, and washed and developed using a chemiluminescent detection system. Finally, the membranes were stripped with stripping buffer (Thermo Scientific, Fisher Scientific) for 20 min, blocked again, and reprobed with a rabbit anti- $\beta$-actin (1:3000, Cell Signaling Technologies) polyclonal antibody as a loading control. Densitometry values from the samples were acquired using NIH Image and were normalized to their respective $\beta$-actin values.

Chemicals. Except for the CB1R antagonist, $N$-(piperidin-1-yl)-5(4-chlorophenyl)-1-(2,4-dichlorophenyl)-4-methyl-1 $H$-pyrazole-3carboxamide hydrochloride (SR141716A), all drugs were made up as $1000 \times$ stocks in distilled water, divided into $20 \mu \mathrm{l}$ aliquots, and frozen at $-20^{\circ} \mathrm{C}$ until use. SR141716A was made up in DMSO; final DMSO concentration in the bath was $0.02 \%$. Once thawed, aliquots were either used or discarded within 2 months after preparation; none were refrozen and reused. Drugs were obtained from Tocris Bioscience [DHPG and 2-methyl-6(phenylethynyl)-pyridine (MPEP)], Ascent Scientific [NBQX, D-AP5, and 6-amino- $N$-cyclohexyl- $N, 3$-dimethylthiazolo[3,2-a]benzimidazole-2-carboxamide (YM298198)], and National Institute on Drug Abuse (SR141716A). All other drugs and chemicals were purchased from Sigma-Aldrich.

Data analysis. $t$ tests were used for single comparisons. Statistical tests among groups were done with one-way ANOVA. The significance level for all tests was $p<0.05\left(^{*}\right)$. Group means \pm SEMs are shown for display purposes. For comparison of cumulative distribu- 


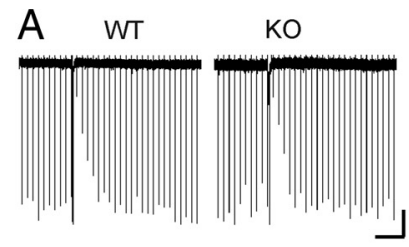

B

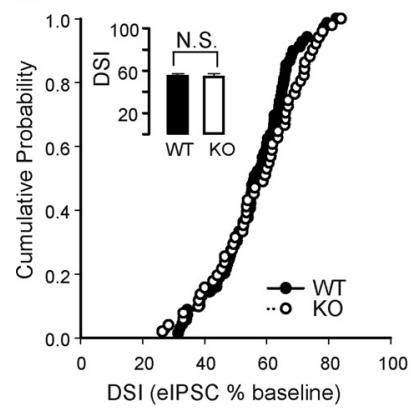

C
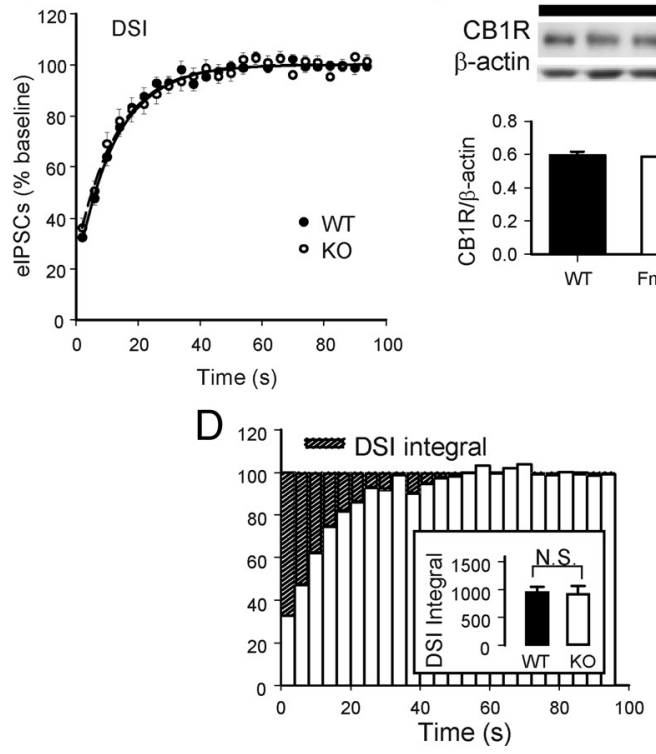

Figure 2. FMRP deficiency does not alter $\mathrm{Ca}^{2+}$-dependent eCB mobilization, $\mathrm{CB} 1 \mathrm{R}$ responsiveness, or protein expression levels of mGluR1, mGluR5, or CB1R. $A$, Representative traces showing DSI induced by a $1 \mathrm{~s} \mathrm{step} \mathrm{depolarization} \mathrm{in} \mathrm{WT} \mathrm{(left)} \mathrm{and} \mathrm{Fmr} 1 \mathrm{KO}$ (right) mice. Calibration: WT, 200 pA, 0.5 min; Fmr1 K0, 150 pA, 0.5 min. B, Cumulative probability plot of DSI magnitudes recorded in WT (black circles) and Fmr1 $\mathrm{KO}$ (white circles) mice; difference n.s. by K-S test. Inset, Mean DSI magnitudes: WT mice: $56.0 \pm 1.5 \%, n=69 ;$ Fmr1 K0 mice: $55.2 \pm$ $2.2 \%, n=51$ (difference n.s. by $t$ test). C, The time course of decay of DSI ( $n=24$ trials, 1 trial each in 24 cells). $\boldsymbol{D}$, DSl integral shaded area (see Materials and Methods). Inset, Mean DSl integrals did not differbetween Fmr1 K0 and WT mice. WT:967.1 $\pm 82.6 \% \cdot s ; \mathrm{Fmr} 1 \mathrm{K0}: 936.8 \pm 127.7 \% \cdot s, p>$ 0.1. $E-G$, Representative photomicrographs and grouped data of Western blots from hippocampal tissue in all sections. Blot densities measured with $\mathrm{NIH} \mathrm{Image.} \mathrm{The} \mathrm{densitometry} \mathrm{values} \mathrm{were} \mathrm{normal-}$ ized to their respective $\beta$-actin values. E, mGluR5 from WT $(n=5), \mathrm{mGluR5}^{-1-}(n=2)$, and Fmr1 $\mathrm{KO}(n=6)$ mice. $\boldsymbol{F}$, mGluR1 from WT $(n=5)$, mGluR1 ${ }^{-1-}(n=3)$, and Fmr1 KO $(n=4)$ mice. G, CB1R from WT $(n=4)$ and Fmr1 KO $(n=4)$ mice.

tions, we used the Kolmogorov-Smirnov (K-S) test, available at http://www.physics.csbsju.edu/stats/KS-test.n.plot_form.html.

\section{Results}

mGluRs mobilize eCBs in Fmr1 KO mice more effectively than in C57BL/6J WT mice

To determine whether mGluR-dependent eCB-iSTD is different in CA1 pyramidal neurons from Fmr1 $\mathrm{KO}$ and WT mice, both C57BL/6J, we bath applied the selective Gp1 agonist, DHPG, at
A
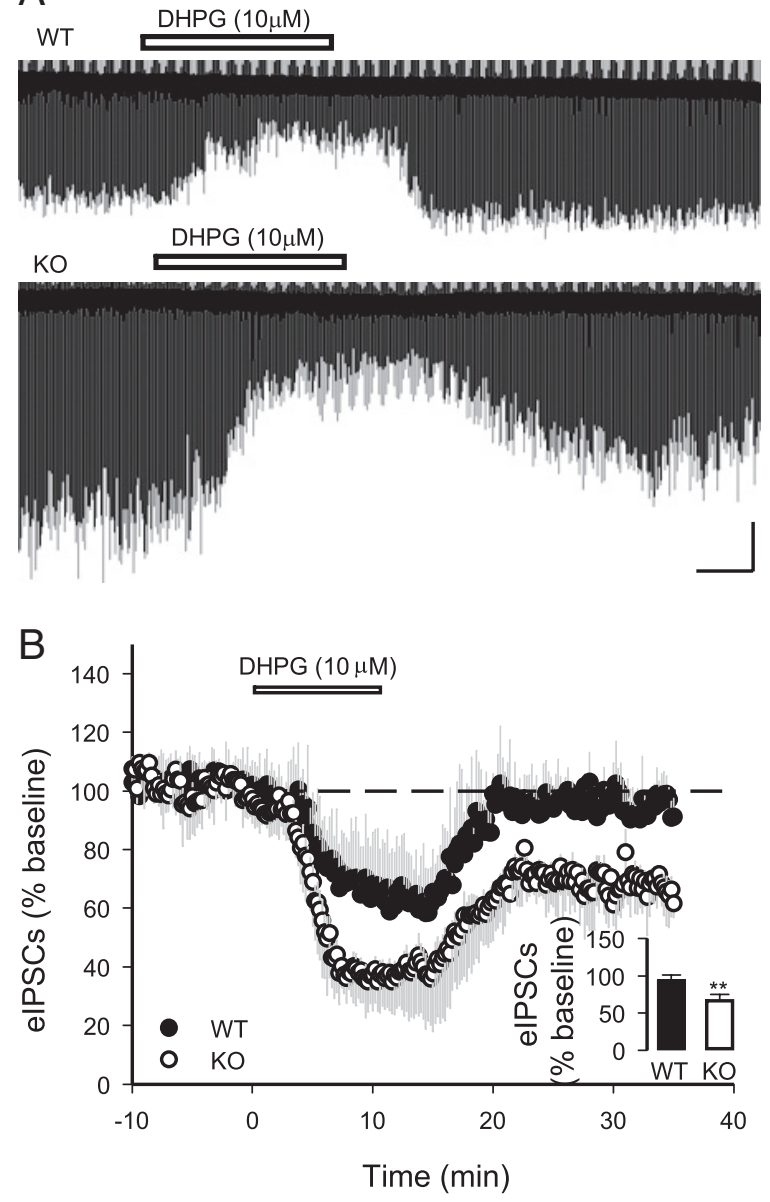

Figure 3. Low dose of DHPG induceseCB-iLTD in Fmr1 KO butnot in WT mice. $A$, Representativetraces. Calibration: 200 pA, 3 min. B, Grouped data obtained from WT (black circles) and Fmr1 K0 (white circles) mice. Inset, Summary of mean elPSC depression measured $20-25$ min after DHPG washout. WT mice: $94.8 \pm 3.2 \%, n=4$; Fmr1 KO mice: $68.5 \pm 3.0 \%, n=5, p<0.01$.

concentrations from 1 to $50 \mu \mathrm{M}$ for 3-4 min (Fig. $1 A$ ). At doses of $>2 \mu \mathrm{M}$, DHPG reduced eIPSCs in both WT and Fmr1 KO mice. The responses were similar at the highest doses; however, at intermediate concentrations, DHPG suppressed eIPSCs more effectively in Fmr1 KO mice. In WT mice, 5, 10, and $20 \mu \mathrm{M} \mathrm{DHPG}$ reduced eIPSC amplitudes to $81.6 \pm 3.9 \%, 72.5 \pm 3.4 \%$, and $45.7 \pm 7.6 \%$ of control, respectively. In Fmr1 KO mice, the same doses reduced eIPSC amplitudes to $70.2 \pm 5.5 \%, 45.2 \pm 4.6 \%$, and $36.3 \pm 4.2 \%$ of control, respectively. At $50 \mu \mathrm{M}$, DHPG reduced eIPSC similarly in both strains (to $31.4 \pm 7.1 \%$ of control, WT, $n=7$ and to $29.8 \pm 4.4 \%$ of control, Fmr1 KO, $n=6)$. The group data, fit with sigmoidal curves, suggest that the doseresponse relationship is shifted to the left in Fmr1 KO mice (Fig. $1 B)$. The largest difference was apparent at $10 \mu \mathrm{M} \mathrm{DHPG}$, as shown by cumulative probability distributions of the eIPSC suppressions $(\mathrm{K}-\mathrm{S}$ test, $p<0.01$ ) (Fig. $1 C$ ). Hence, $10 \mu \mathrm{M}$ DHPG was used in subsequent experiments, except as noted. The Gp1 antagonists, MPEP $(10 \mu \mathrm{M})$ plus YM298198 $(4 \mu \mathrm{M})$ for $>1 \mathrm{~h}$, prevented DHPG from suppressing eIPSC amplitudes (Fig. $1 B$, gray triangle) $(n=4)$, showing that the DHPG effects are Gp1 mGluR dependent. Finally, the CB1R antagonist, SR141716A, $5 \mu \mathrm{M}$ (slices pretreated for $>2 \mathrm{~h}$ and SR141716A continuously bath applied), prevented the effects of DHPG in Fmr1 KO slices $(n=$ 7). Thus, DHPG suppresses eIPSCs by activating Gp1 mGluRs and mobilizing eCBs in Fmr1 KO mice. 

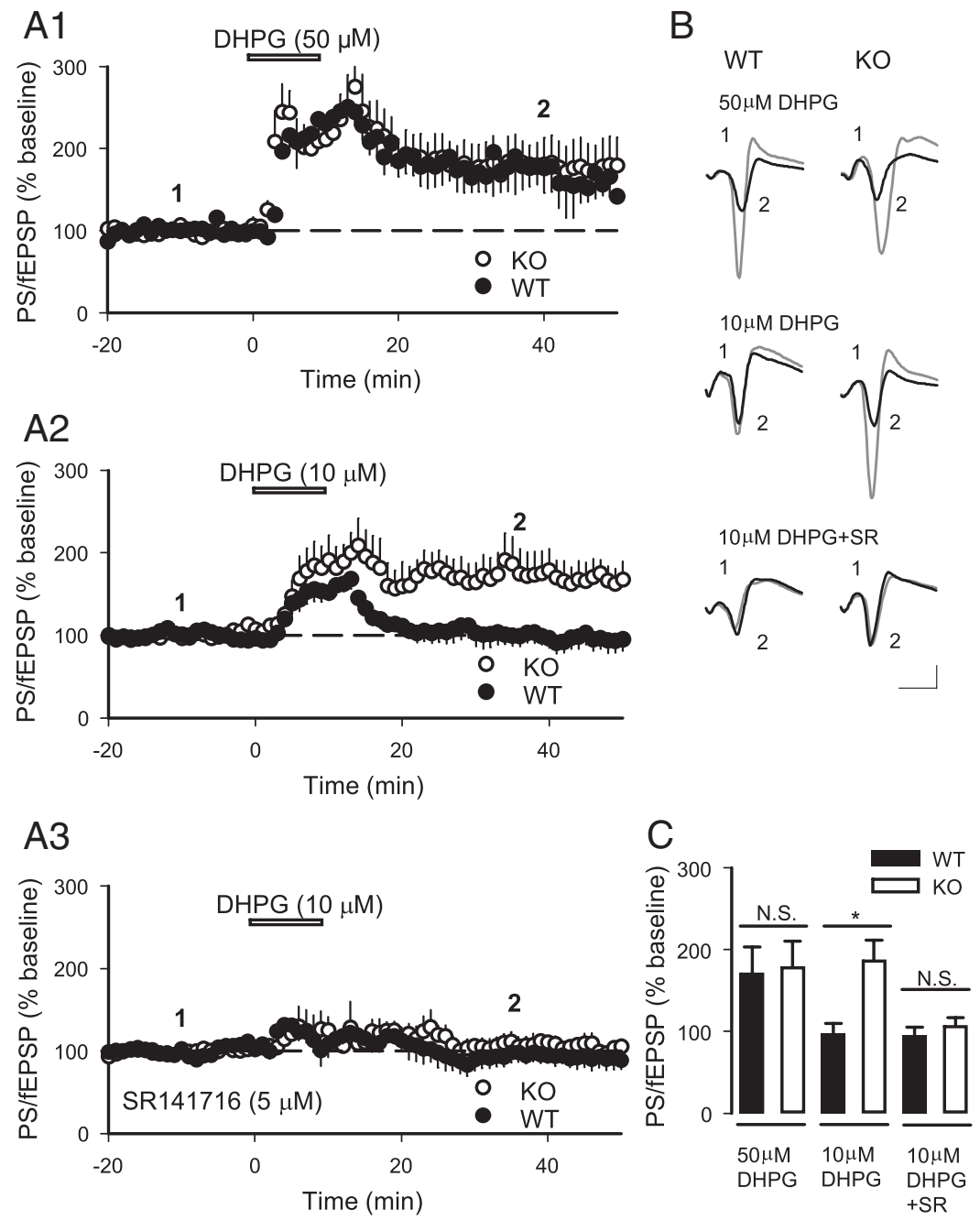

Figure 4. E-S coupling potentiation in Fmr1 KO and WT mice. A1, DHPG $(50 \mu \mathrm{M})$ applied for 10 min induced $\mathrm{E}-\mathrm{S}$ coupling potentiation in both WT and Fmr1 KO mice. A2, DHPG $(10 \mu \mathrm{M})$ applied for 10 min induced strong $\mathrm{E}-\mathrm{S}$ coupling potentiation in Fmr1 KO mice, but had only a modest effect in WT mice. A3, Pretreatment and continuous presence of $5 \mu \mathrm{m}$ SR141716A blocked E-S coupling potentiation in Fmr1 KO mice. $\boldsymbol{B}$, Representative traces. Calibration: $1 \mathrm{mV}, 5 \mathrm{~ms}$. C, Summary of E-S coupling potentiation measured 35-45 min after DHPG washout. DHPG $(50 \mu \mathrm{M})$, WT mice: $172.1 \pm 31.5 \%, n=5$; Fmr1 K0 mice: $179.7 \pm 30.5 \%, n=$ 7, $p>0.1$; DHPG $(10 \mu \mathrm{M})$, WT mice: $98.0 \pm 11.8 \%, n=7$; Fmr1 K0 mice: $187.8 \pm 23.7 \%, n=6, p<0.01$; in the presence of SR141716A plus DHPG, WT mice: $94.9 \pm 10.6 \%, n=5 ;$ Fmr1 K0 mice: $107.7 \pm 8.9 \%, n=6, p>0.1$.

Fmr1 KO mice seem to have heightened responsiveness to DHPG, but alternatively, C57BL/6J WT mice might have abnormally low responsiveness that is absent in the KO. To test this possibility, we applied $10 \mu \mathrm{M}$ DHPG to pyramidal cells in slices from WT C57BL/6N male mice, or female WT $129-\mathrm{Sv}$ or CD1 mice. DHPG-induced eIPSC suppressions among all WT mice were indistinguishable, and significantly smaller than responses of the KO mice (supplemental Fig. 1, available at www.jneurosci. org as supplemental material). The time to peak $\left(t_{1 / 2}\right)$ of the eIPSC suppression was not significantly different among the strains (supplemental Fig. 2, available at www.jneurosci.org as supplemental material), showing that DHPG does not have better tissue access in Fmr1 KO mice.

\section{DSI did not differ between Fmr1 KO and WT mice}

To test for eCB system differences, we compared the transient, $\mathrm{Ca}^{2+}$-induced, eCB-mediated reduction of eIPSCs, DSI, in hippocampal CA1 pyramidal neurons from Fmr1 KO and WT mice. DSI reduced eIPSCs in both WT $(n=69)$ and Fmr1 KO $(n=51)$ mice (Fig. 2A,B). Recovery from DSI was determined by fitting a single-exponential decay function from the peak suppression back to baseline (Fig. 2C) $(n=24)$, and as a final check on the $\mathrm{Ca}^{2+}$-dependent $\mathrm{eCB}$ release process, we also calculated the "DSI integral," which includes information of both peak and duration of the eCB effects (see Materials and Methods). The DSI decay time constants and integrals were essentially identical in both groups. Neither $t$ tests nor K-S tests revealed a significant difference between Fmr1 KO and WT mice for DSI magnitude, decay, or integral values. Therefore, deletion of FMRP does not affect any of the following: (1) $\mathrm{CB} 1 \mathrm{R},(2) \mathrm{eCB}$ release from pyramidal cells, or (3) the coupling between the rise in postsynaptic $\left[\mathrm{Ca}^{2+}\right]_{\mathrm{i}}$ and eCB mobilization.

\section{Protein expression of mGluR1, mGluR5, or CB1R is unchanged in Fmr1 KO mice}

Several mechanisms could underlie the increased ability of mGluRs to induce eCBmediated responses in Fmr1 $\mathrm{KO}$ mice, including enhanced CB1R expression or downstream effectors, or increases in mGluR1, mGluR5, or coupling between mGluRs and eCB mobilization. Western blot analyses revealed no differences between Fmr1 KO and WT mice in expression of any of these receptors (Fig. 2E-G). Hence, increased receptor number does not explain the increased sensitivity to DHPG in Fmr1 KO mice; rather, coupling between the mGluRs and eCB mobilization could be responsible.

\section{mGluR-dependent eCB-iLTD is enhanced in Fmr1 KO mice}

Prolonged activation $(\sim 10 \mathrm{~min})$ of $\mathrm{Gp} 1$ mGluRs with $50 \mu \mathrm{M}$ DHPG produces eCB-iLTD (Chevaleyre and Castillo, 2003; Edwards et al., 2006); lower DHPG concentrations generally do not. If coupling between mGluRs and eCB mobilization is enhanced in Fmr1 KO mice, then lower DHPG concentrations might be able to induce eCB-iLTD in these mice. To test this prediction, we applied $10 \mu \mathrm{M}$ DHPG to slices of both Fmr1 KO and WT mice for $10 \mathrm{~min}$. The eIPSCs were suppressed to $62.1 \pm 4.6 \%$ of baseline in WT mice and $36.3 \pm 3.9 \%$ of baseline in Fmr1 KO mice during DHPG application (Fig. $3 A, B)(p<0.01)$. However, $20 \mathrm{~min}$ after washout of DHPG, the eIPSCs returned to baseline $(n=4)$ in WT mice, but remained depressed $(n=5, p<0.01)$ (Fig. $3 B$ ) in Fmr1 KO mice.

\section{CB1R-dependent $\mathrm{E}-\mathrm{S}$ coupling potentiation is enhanced in Fmr1 KO mice}

A lasting decrease GABAergic inhibition underlies the form of LTP called E-S coupling potentiation (Chevaleyre and Castillo, 2003); thus, E-S coupling should be facilitated in Fmr1 KO mice. A 10 min application of $50 \mu \mathrm{M}$ DHPG strongly potentiated E-S coupling 35-45 min after DHPG application in both WT $(n=5)$ 
and Fmr1 KO $(n=7)$ mice (Fig. $4 A 1$, typical traces in Fig. $4 B)$. However, $10 \mu \mathrm{M}$ DHPG applied for $10 \mathrm{~min}$ induced strong E-S coupling potentiation in Fmr1 KO (Fig. 4A2) $(n=6)$ but only a slight effect in WT $(n=7)$ mice $(p<0.05)$. SR141716A prevented $\mathrm{E}-\mathrm{S}$ coupling potentiation in both groups (Fig. $4 A 3)(n=$ 6 , Fmr1 KO; $n=5$, WT).

\section{Discussion}

Our results reveal that FMRP deficiency in C57BL/6J mice leads to increased neuronal excitability mediated by eCBs. The ability of Gp1 mGluRs to mobilize eCBs is heightened in Fmr1 KO animals, resulting in more pronounced eCB-iSTD, as well as greater susceptibility to eCB-iLTD, and E-S coupling potentiation. By altering mechanisms of synaptic plasticity, these factors could contribute to the cognitive dysfunctions associated with FXS.

eCBs are mobilized by two kinds of cellular stimulation: a strong rise in $\left[\mathrm{Ca}^{2+}\right]_{\mathrm{i}}$ or activation of certain G-protein-coupled receptors, such as Gp1 mGluRs (Maejima et al., 2001; Varma et al., 2001). Activation of Gp1 mGluRs stimulates local translation of synaptic mRNAs (Weiler and Greenough, 1993; Merlin et al., 1998; Huber et al., 2000; Bear et al., 2004), including the mRNA that encodes FMRP (Weiler and Greenough, 1999). Our data suggest that FMRP is involved in regulating mGluRdependent mobilization of eCB. Similarities in magnitude and duration of DSI in Fmr1 KO and WT mice suggested that FMRP did not affect $\mathrm{Ca}^{2+}$-induced mobilization of eCBs, CB1Rs, or the effector mechanisms that inhibit GABA release downstream of CB1R. Maximal responses produced by DHPG were unaffected by FMRP deficiency, implying that the coupling between mGluRs and $\mathrm{eCB}$ mobilization may be quantitatively, but not qualitatively, altered. Data from Western blots of mGluRs and CB1Rs, together with the increased capacity of moderate concentrations of DHPG to initiate eCB-dependent responses, support the conclusion that the coupling between mGluRs and eCB mobilization is modulated by FMRP.

The mechanism of FMRP modulation of eCB mobilization cannot be determined without more information on the pathway between mGluRs and the signaling pool of eCBs (probably 2-AG) (e.g., Hashimotodani et al., 2005). eCBs are derived directly from membrane lipids (Piomelli, 2003), and it is unlikely that FMRP is immediately involved in this process. Nevertheless, cellular proteins regulated by FMRP may play some role. Diacylglycerol lipase meditates 2-AG synthesis (Piomelli, 2003), and gene knock-out experiments show that $\mathrm{PLC}_{\beta 1}$ is upstream of eCB mobilization in the hippocampus (Hashimotodani et al., 2005), although obligatory activation $\mathrm{PLC}_{\beta 1}$ before brief, phasic release of eCBs has not been demonstrated (Hashimotodani et al., 2005; Edwards et al., 2008). A presently uncharacterized transporter participates in eCB release in some circumstances (Adermark and Lovinger, 2007; Edwards et al., 2008), and might constitute another potential target for FMRP regulation. Understanding the connections between FMRP and eCB mobilization will be an important goal of future studies.

Bear and colleagues (Bear et al., 2004; Dölen et al., 2007) have put forward an "mGluR theory of fragile X mental retardation," which holds that dysfunction of Gp1 mGluR effector mechanisms stemming from FMRP deficiency may cooperate in shaping the FXS phenotype. Because eCB mobilization is downstream of these mGluRs, our study effectively tested a prediction of the theory, and our results are broadly consistent with it. Importantly, though less obviously, our data may also help account for some poorly understood details of FXS-related phenomena. For instance, enhancement of eCB-iLTD (Fig. 3) could foster the "hyperplasticity" represented by enhanced LTD in the CA1 (Huber et al., 2002). Approximately 25\% of FXS patients suffer from epilepsy during development (Sabaratnam et al., 2001), and seizure activity is often increased by suppression of GABA inhibition. Prolonged epileptiform discharges can be mediated by altered activation of Gp1 mGluRs in Fmr1 KO mice (Chuang et al., 2005; Bianchi et al., 2009); however, in these experiments bicuculline is usually used to block GABA responses and induce epileptiform discharges. Perhaps the disinhibition represented by eCB-iLTD contributes to initial changes of pyramidal cell excitability, and thus sets the stage for the prolonged seizure states. The endocannabinoid system could represent another target for intervention in the treatment of FXS.

\section{References}

Adermark L, Lovinger DM (2007) Retrograde endocannabinoid signaling at striatal synapses requires a regulated postsynaptic release step. Proc Natl Acad Sci U S A 104:20564-20569.

Alger BE (2002) Retrograde signaling in the regulation of synaptic transmission: focus on endocannabinoids. Prog Neurobiol 68:247-286.

Bear MF, Huber KM, Warren ST (2004) The mGluR theory of fragile X mental retardation. Trends Neurosci 27:370-377.

Bianchi R, Chuang SC, Zhao W, Young SR, Wong RK (2009) Cellular plasticity for group I mGluR-mediated epileptogenesis. J Neurosci 29:3497-3507.

Brown V, Jin P, Ceman S, Darnell JC, O’Donnell WT, Tenenbaum SA, Jin X, Feng Y, Wilkinson KD, Keene JD, Darnell RB, Warren ST (2001) Microarray identification of FMRP-associated brain mRNAs and altered mRNA translational profiles in fragile X syndrome. Cell 107:477-487.

Carlson G, Wang Y, Alger BE (2002) Endocannabinoids facilitate the induction of LTP in the hippocampus. Nat Neurosci 5:723-724.

Chevaleyre V, Castillo PE (2003) Heterosynaptic LTD of hippocampal GABAergic synapses. A novel role of endocannabinoids in regulating excitability. Neuron 38:461-472.

Chuang SC, Zhao W, Bauchwitz R, Yan Q, Bianchi R, Wong RK (2005) Prolonged epileptiform discharges induced by altered Gp1 metabotropic glutamate receptor-mediated synaptic responses in hippocampal slices of a fragile X mouse model. J Neurosci 25:8048-8055.

de Vries BB, Halley DJ, Oostra BA, Niermeijer MF (1998) The fragile X syndrome. J Med Genet 35:579-589.

Dölen G, Osterweil E, Rao BS, Smith GB, Auerbach BD, Chattarji S, Bear MF (2007) Correction of fragile X syndrome in mice. Neuron 56:955-962.

Edwards DA, Kim J, Alger BE (2006) Multiple mechanisms of endocannabinoid response initiation in hippocampus. J Neurophysiol 95:67-75.

Edwards DA, Zhang L, Alger BE (2008) Metaplastic control of the endocannabinoid system at inhibitory synapses in hippocampus. Proc Natl Acad Sci U S A 105:8142-8147.

Feng Y, Gutekunst CA, Eberhart DE, Yi H, Warren ST, Hersch SM (1997) Fragile $\mathrm{X}$ mental retardation protein: nucleocytoplasmic shuttling and association with somatodendritic ribosomes. J Neurosci 17:1539-1547.

Hashimotodani Y, Ohno-Shosaku T, Tsubokawa H, Ogata H, Emoto K, Maejima T, Araishi K, Shin H-S, Kano M (2005) Phospholipase C $\beta$ serves as a coincidence detector through its $\mathrm{Ca} 2+$ dependency for triggering retrograde endocannabinoid signal. Neuron 45:257-268.

Hou L, Antion MD, Hu D, Spencer CM, Paylor R, Klann E (2006) Dynamic translational and proteasomal regulation of fragile $\mathrm{X}$ mental retardation protein controls mGluR-dependent long-term depression. Neuron 51:441-454.

Huber KM, Kayser MS, Bear MF (2000) Role for rapid dendritic protein synthesis in hippocampal mGluR-dependent long-term depression. Science 288:1254-1257.

Huber KM, Gallagher SM, Warren ST, Bear MF (2002) Altered synaptic plasticity in a mouse model of fragile $\mathrm{X}$ mental retardation. Proc Natl Acad Sci U S A 99:7746-7750.

Jin P, Warren ST (2000) Understanding the molecular basis of fragile X syndrome. Hum Mol Genet 9:901-908. 
Katona I, Sperlágh B, Sík A, Käfalvi A, Vizi ES, Mackie K, Freund TF (1999) Presynaptically located CB1 cannabinoid receptors regulate GABA release from axon terminals of specific hippocampal interneurons. J Neurosci 19:4544-4558.

Koekkoek SK, Yamaguchi K, Milojkovic BA, Dortland BR, Ruigrok TJ, Maex R, De Graaf W, Smit AE, VanderWerf F, Bakker CE, Willemsen R, Ikeda T, Kakizawa S, Onodera K, Nelson DL, Mientjes E, Joosten M, De Schutter E, Oostra BA, Ito M, et al. (2005) Deletion of FMR1 in Purkinje cells enhances parallel fiber LTD, enlarges spines, and attenuates cerebellar eyelid conditioning in fragile X syndrome. Neuron 47:339-352.

Lenz RA, Wagner JJ, Alger BE (1998) N- and L-type calcium channel involvement in depolarization-induced suppression of inhibition in rat hippocampal CA1 cells. J Physiol 512:61-73.

Maejima T, Hashimoto K, Yoshida T, Aiba A, Kano M (2001) Presynaptic inhibition caused by retrograde signal from metabotropic glutamate to cannabinoid receptors. Neuron 31:463-475.

Merlin LR, Bergold PJ, Wong RKS (1998) Requirement of protein synthesis for Gp1 mGluR-mediated induction of epileptiform discharges. J Neurophysiol 80:989-993.
O'Donnell WT, Warren ST (2002) A decade of molecular studies of fragile X syndrome. Annu Rev Neurosci 25:315-338.

Pfeiffer BE, Huber KM (2006) Current advances in local protein synthesis and synaptic plasticity. J Neurosci 26:7147-7150.

Piomelli D (2003) The molecular logic of endocannabinoid signaling. Nat Rev Neurosci 4:873-884.

Sabaratnam M, Vroegop PG, Gangadharan SK (2001) Epilepsy and EEG findings in 18 males with fragile X syndrome. Seizure 10:60-63.

Varma N, Carlson GC, Ledent C, Alger BE (2001) Metabotropic glutamate receptors drive the endocannabinoid system in hippocampus. J Neurosci 21:RC188(1-5).

Weiler IJ, Greenough WT (1993) Metabotropic glutamate receptors trigger postsynaptic protein synthesis. Proc Natl Acad Sci U S A 90:71687171.

Weiler IJ, Greenough WT (1999) Synaptic synthesis of the fragile X protein: possible involvement in synapse maturation and elimination. Am J Med Genet 83:248-252.

Wilson RI, Kunos G, Nicoll RA (2001) Presynaptic specificity of endocannabinoid signaling in the hippocampus. Neuron 31:453-462. 